\title{
Eccrine porocarcinoma: A case report and review of the literature
}

\author{
Mark Sheldon Lloyd MRCS(Eng), Naguib El-Muttardi FRCS, A Robson MRCPath
}

\begin{abstract}
MS Lloyd, N El-Muttardi, A Robson. Eccrine porocarcinoma: A case report and review of the literature. Can J Plast Surg 2003;11(3):153-156.
\end{abstract}

Eccrine porocarcinoma is a rare form of skin cancer that is often confused with other types of skin malignancy. The present paper highlights a typical case to remind plastic surgeons of the natural history, pathological findings and current literature on the management of this cancer.

Key Words: Eccrine porocarcinoma; Plastic surgery; Sweat gland tumours

\section{Le porocarcinome eccrine : Rapport de cas et analyse bibliographique}

Le porocarcinome eccrine est une rare forme de cancer cutané souvent confondue avec d'autres types de malignité cutanée. Le présent article met en lumière un cas type pour rappeler aux plasticiens l'évolution naturelle, les observations pathologiques et la documentation scientifique actuelle sur la prise en charge de ce type de cancer.

\section{CASE PRESENTATION}

A 79-year-old white gentleman was seen in clinic with a suspicious skin lesion on his right leg. This had been noticed over a three month period. Alarming features included a rapid increase in size, foul odour and fungating fleshy appearance. There had been no history of excess ultraviolet radiation exposure or trauma, and his past medical history was unremarkable.

On examination, the suspicious skin lesion was on the lateral part of the right leg, measuring $1 \times 2 \mathrm{~cm}$ in diameter with the characteristics described above. Examination of the right groin at that time was unremarkable. He was booked for surgery one month later.

Re-examination on admission showed a marked increase in the size of the lesion. A large, palpable lymph node was now present in the groin. Fine needle aspiration cytology of the lymph node suggested squamous cell carcinoma. Computerised tomographic scanning of the thorax, abdomen and pelvis showed no signs of disease proximal to the right groin.

The problematic lesion was resected with a $2 \mathrm{~cm}$ margin and reconstructed with a split thickness skin graft. A right groin dissection was performed and submitted for analysis. Histological examination showed an ulcerated epithelial tumour with eosinophilic cohesive cells with marked keratinisation. There was considerable atypia with cytological pleomorphism, irregular and often hyperchromatic nuclei and frequent mitotic figures (Figure 1). Sweat duct differentiation was identified by haemotoxylin and eosin and periodic acid Schiff staining. Accordingly, a diagnosis of eccrine porocarcinoma was made.

The surgical excision margins were reported as completely clear. The pathological examination of the resected lymph nodes confirmed metastatic deposits in the groin.

Three weeks after surgery, small fleshy nodules were noticed at the margins of the excision site. These were confirmed as cutaneous metastases on punch biopsy and a wider resection was done with the margins reported clear yet again (Figure 2). The patient remained well for the next fortnight. Just before discharge, a further nodule had developed amidst the clear margins of the previous two resections. Under the joint care of the oncologists and plastic surgery team, further surgery was thought inappropriate and his condition was not amenable to chemotherapy or radiotherapy. Figure 3 shows the affected limb before the patient's death.

\section{DISCUSSION}

History of literature surrounding eccrine porocarcinoma The conception of cutaneous carcinomas showing sweat gland differentiation was first reported in the mid-1800s $(1,2)$. There were problems reporting the lesions due to their rarity and variation in histological appearances. In 1943, the data were summarized by Gates et al (3), but it was Stout and Cooley (4) who produced the first series of tumours all analysed by the same authors. In 1963, Pinkus and Mehregan (5) reported the first case of eccrine porocarcinoma in the literature. This was a glycogen-rich tumour in an 82-year-old woman with multiple cutaneous metastases and lymph node deposits. The patient died.

\begin{abstract}
Anatomy of the sweat duct apparatus
Human skin consists of sebaceous glands and sweat glands. The sweat glands may be apocrine or eccrine glands, but it is difficult to differentiate between the two. Apocrine glands may be found in the axilla, anogenital area, mammary glands and the ceruminous glands of the external auditory canal and eyelid (7). Developmentally, they are appendages of the hair follicles that mature during adolescence and produce a distinctive odour when bacteria break down their secretions.

Eccrine glands are found everywhere on the body except the glans penis, clitoris, labia minora and the inner surface of the prepuce (8). The most dense areas are the palms of the
\end{abstract}

Department of Plastic Surgery and St John's Institute of Dermatology, St Thomas' Hospital, London, United Kingdom

Correspondence and reprints: Mr Naguib El-Muttardi, St Thomas' Hospital, Plastic Surgery, 3rd Floor Lambeth Wing, Lambeth Palace Road

SE1 7EH England. Telephone 020-7928-9292 ext 8189, fax 020-7922-8186, e-mail MSL@doctors.org.uk 

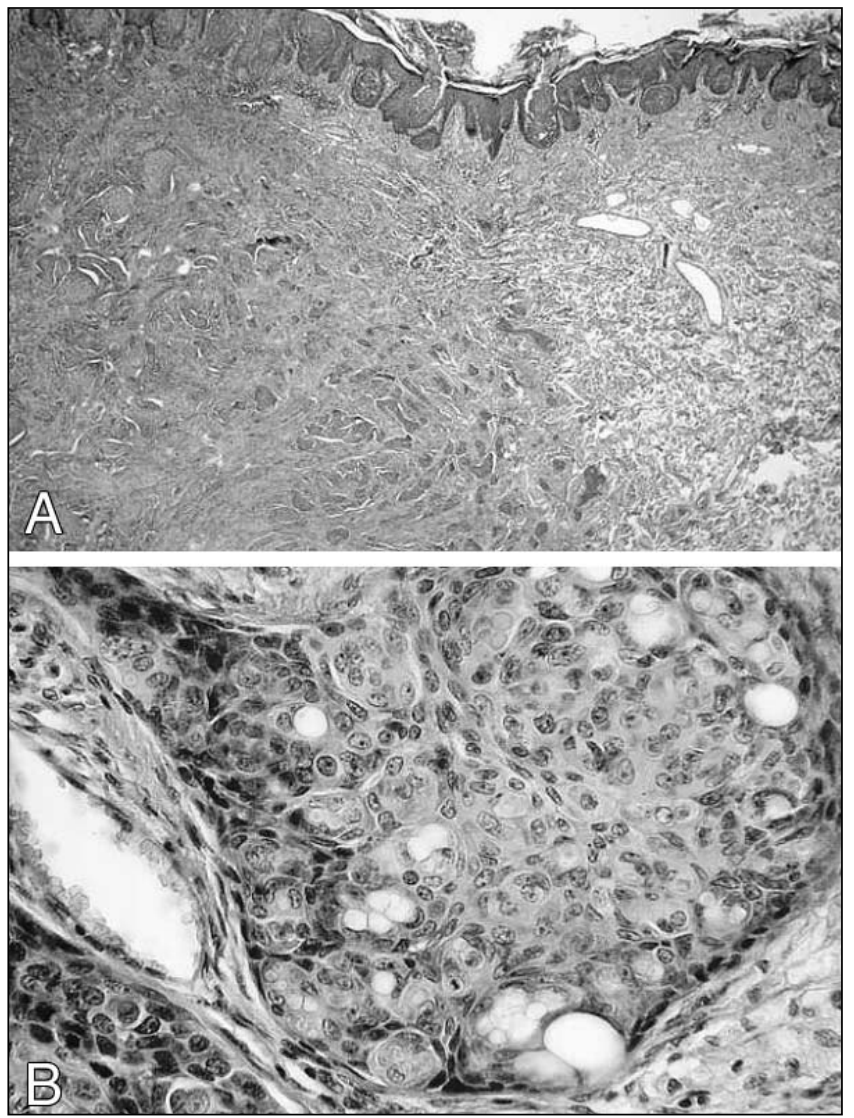

Figure 1) A The intraepidermal part of the tumour extends all across the top of the picture. The invasive part is on the left part of the picture extending to the base. B On the left, there is intracytoplasmic sweat gland lumen formation, another characteristic feature

hands, soles of the feet, head, trunk and extremities. No new glands are formed after birth.

The function of eccrine skin glands in the face and trunk is thermal regulation via evaporative heat loss. Eccrine glands in the palm and soles of the feet increase gripping strength. The control of the glands is via local and central means. The glands are long, unbranched, closely coiled secretory tubules which secrete sweat through a long excretory duct. The ducts are located in the dermis and epidermis. The straight intradermal portion of the duct is the syrinx, and the coiled intradermal portion opening onto the skin surface is the acrosyringium $(9,10)$. Tumours of the syrinx are termed syringomas and tumours of the acrosyringium are poromas. The term porocarcinoma was introduced by Mishima and Morioka in 1969 (11) after Pinkus reported his case.

Pinkus (5) first suggested the existence of the eccrine sweat duct unit, the acrosyringium, in 1939. The benign variant, 'eccrine poroma' was then described by Pinkus in 1953. Eccrine porocarcinoma is the malignant variant (5).

\section{Incidence}

The largest series of cases to date in the literature was by Robson et al (6), from St Thomas' Hospital. The incidence of eccrine porocarcinoma is unclear but has been reported by Wick et al (2) be as low as $0.005 \%$ and $0.01 \%$ by Mehregan et al (12). It is mainly a tumour of the elderly, affecting patients as young as 50 to over 80 years of age.

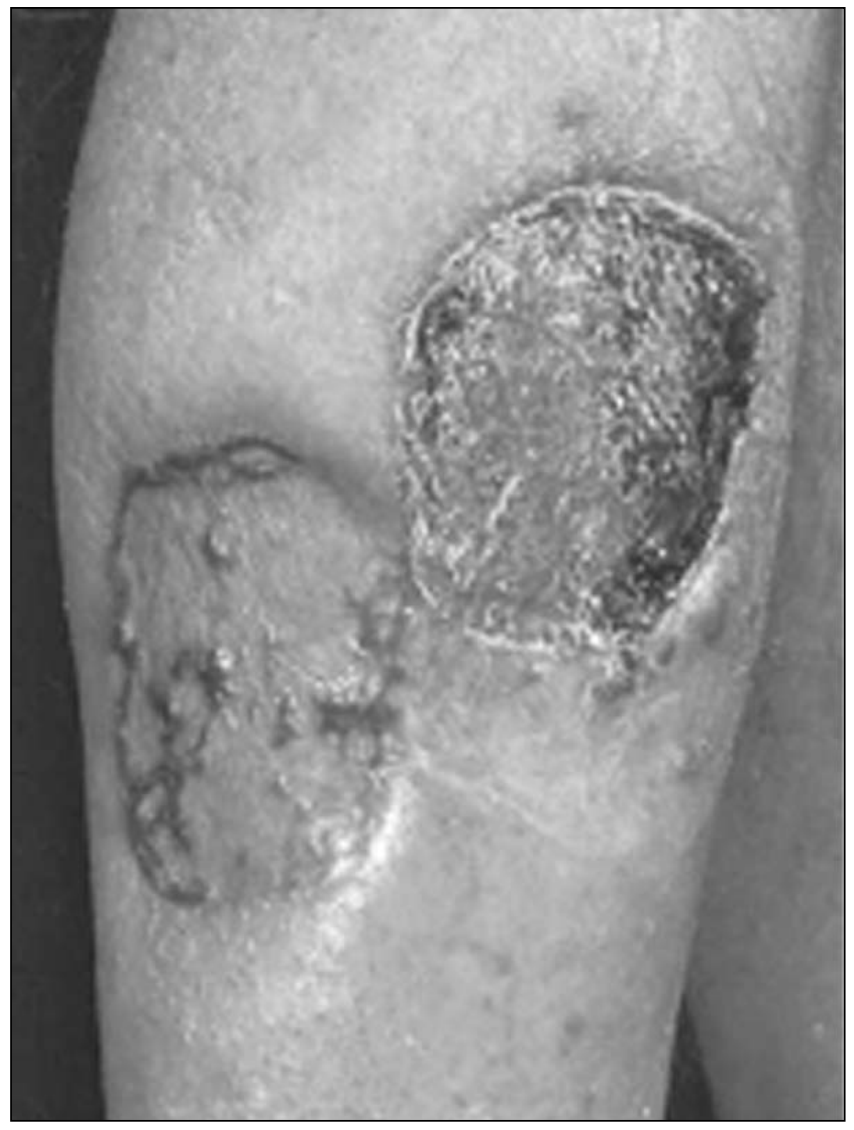

Figure 2) Recurrence after previous clear resection

\section{Natural history}

The etiology of eccrine porocarcinoma is unknown $(2,6,10,13,14)$. Radiation therapy, solar damage and immunosuppression have all been suggested as possible causes, but there is no clear evidence to support this.

The trunk, head, neck and lower extremity are the most common sites in up to $50 \%$ of cases. Less frequent sites include the ear, scalp and face (15). The patient may have a long history of the lesion being present, sometimes up to 50 years $(6,16,17)$. A rapid development of the lesion may occur over a few months. Although the caucasian population is commonly documented in case studies, eccrine porocarcinoma has been reported in Afro Caribbean races (9). The lesions may present as painless papules or nodules with slow evolution and an average growth of four years to clinical presentation $(2,7)$. These nodules may ulcerate or bleed on trauma (18). Sex bias has not been clearly demonstrated in this study, with male and female patients equally affected $(2,6,7,12,15,17-19)$. There may be distant metastases in $25 \%$ of cases to sites such as regional or distant lymph nodes, retroperitoneum, peritoneum, femur, breast, liver, bladder, ovary, adrenal glands, lungs and brain $(6,7,12,15,17-22)$.

\section{Pathological findings}

Several pathological criteria have been found to be diagnostic of eccrine porocarcinoma (6). These have been the presence of an invasive architectural pattern with or without significant 


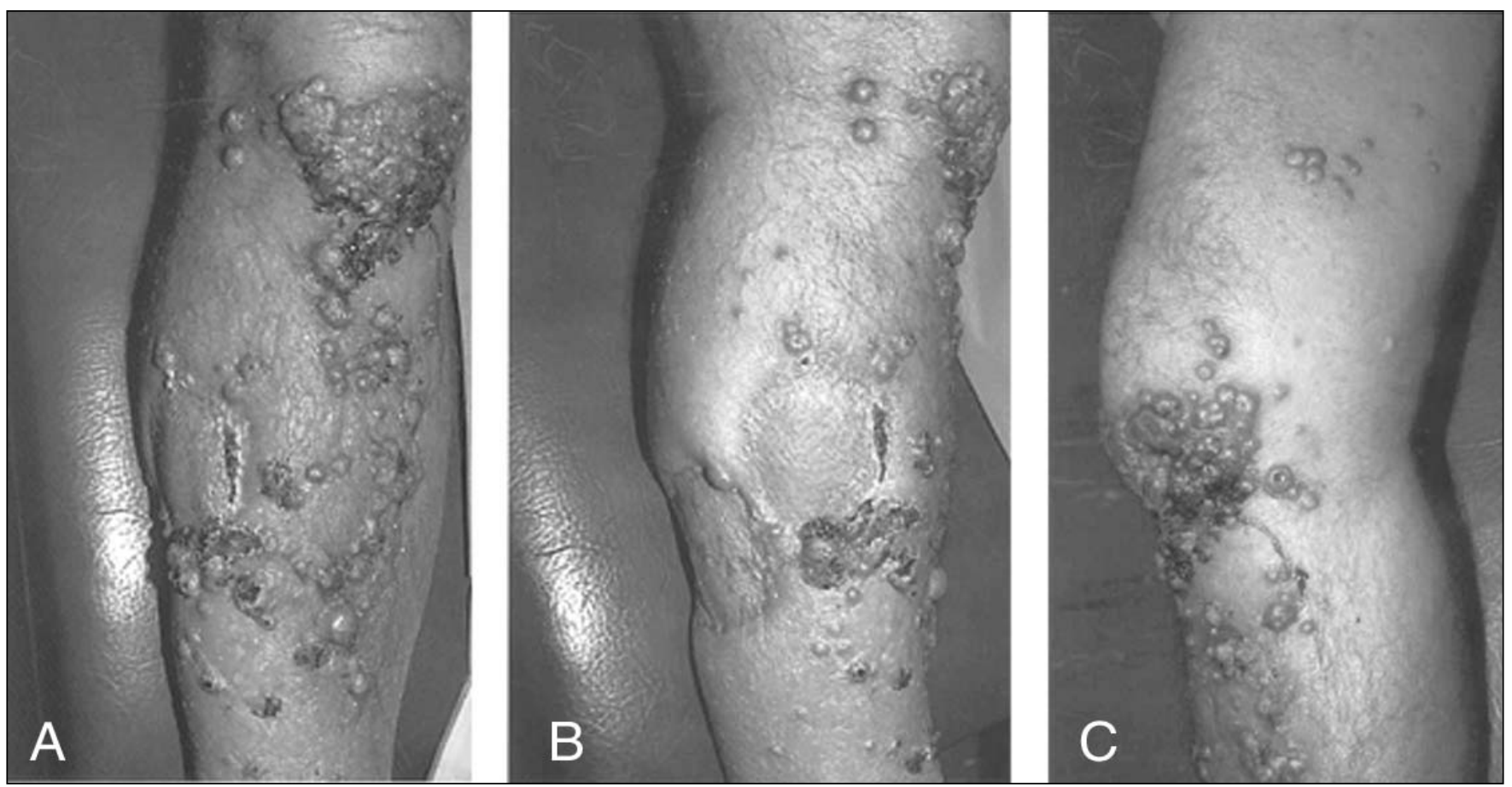

Figure 3) The flesh nodular appearance of the recurrent

cytological pleomorphism in a tumour with eccrine differentiation $(6,10,13,15,18,19,23)$.

The tumours are formed of cohesive basolid epithelial cells. These cells are rich in glycogen and stain positive with the periodic acid Schiff $(6,10,12,1315,19,23)$. Abenzo and Ackerman (24) argued that epithelial cell atypia alone does not mean malignancy, because this is seen in benign eccrine poroma. Thus, the nature of the advancing tumour margin and aggressiveness is the most important factor, irrespective of cytological atypia (6).

The presence of eccrine type ducts may be a prerequisite for the reliable diagnosis of eccrine porocarcinoma; however, using recognizable ducts as a major criterion for diagnosis implies that some poorly differentiated tumours may well be overlooked (6).

Several associated cell types are found with eccrine porocarcinoma, such as squamous cells, spindle cells, clear cells, mucin-producing cells and melanocytes $(6,25)$. The presence of squamous cells in eccrine neoplasia is to be expected because the luminal cells of the acrosyringium are squamous in type. Melanocytes may colonise benign or malignant tumours with the melanin pigment also being present in the metastases, leading to a misdiagnosis of malignant melanoma. Melanocyte-containing benign eccrine tumours are possibly more prevalent in dark-skinned people and may be multiple and grossly pigmented (25). One hypothesis is that sweat ducts have melanocytes during the 14th week of gestation that are lost later on in embryonic development. Whether these melanocytes persist in the sweat gland acrosyringium after foetal life or secrete melanocyte growth factors from tumour cells remains to be seen (13).

The well-formed ducts of eccrine porocarcinoma often stain positive for carcino-embryonic antigen (CEA), which does not happen with malignant melanoma $(2,6,25)$.
The literature suggests that a significant proportion of eccrine porocarinoma follows a pre-existing benign eccrine poroma that undergoes malignant transformation $(6,10,15,26)$.

\section{Prognostic indicators}

Tumour stage is very significant regarding prognosis, and positive lymph node involvement may indicate up to a $65 \%$ mortality $(6,27)$. Several factors have been studied, including mitotic index, lymphovascular invasion, perineural invasion, necrosis, tumour size and depth and the character of the tumour margin. The best prognostic indicators pathologically for a poor outcome seem to be a high mitotic index, lymphovascular invasion and a tumour size and depth greater than $7 \mathrm{~mm}(6)$.

The clinical differential diagnosis of eccrine porocarcinoma should include eccrine poroma, squamous cell carcinoma, malignant melanoma (although these do not test positive with CEA immunocytochemistry) as well as occult visceral neoplasms, occult breast cancer and salivary gland tumours $(2,28)$.

\section{Treatment options}

The local recurrence rate is approximately $25 \%$ (17). The tumour spreads tangentially in the lower third of the epidermis and later infiltrates the dermis subcuticular fat and lymphatic system. The traditional mainstay of treatment has been surgical wide local excision with negative margins with lymphadenectomy if regional lymph nodes are involved $(6,17,21,27,29,30-33)$. The role of sentinal node biopsy is unknown in eccrine porocarcinoma (6). Mohs micrographic surgery has been used successfully to treat five cases, with no reoccurrence over a five-year period in one of the cases (14). Retinoids and interferon have some isolated benefit and there have been no reports or trials in the literature regarding the 
successful use of radiotherapy or chemotherapy $(14,21)$. Abenzo and Ackerman (24) have stated that it is difficult to distinguish primary tumour from metastasis with significant pagetoid spread. It could be that the nest of multiple lesions that are thought to be cutaneous metastases may be part of a true multifocal primary tumour rather than metastatic spread. This could explain the early local skin recurrence despite the clear resection margins which we experienced in our case report.

\section{CONCLUSION}

Eccrine porocaricinoma is a rare aggressive form of skin cancer with unknown etiology and little guidance in the literature on exact protocols for treatment and follow up. It should be on the differential diagnosis of any suspicious skin lesion seen by the plastic surgeon. Close liaison with a pathologist is recommended to avoid incorrect diagnosis.

\section{REFERENCES}

1. Cornil V, cited by Smith. Metastasising carcinoma of sweat glands. Br J Surg 1955;43:80-4.

2. Wick MR, Goellner JR, Wolfe JT. Adnexal carcinomas of the skin. Eccrine porocarcinomas. Cancer 1985;56:1147-62.

3. Gates O, Warren S, Warvi WN. Tumours of sweat glands. Am J Path 1943;19:591-631.

4. Stout AP, Cooley SGE. Carcinoma of the sweat glands. Cancer 1951;4:521-36.

5. Pinkus H, Mehregan AM. Epidermotropic eccrine carcinoma. Arch Dermatol 1963;80:597-606.

6. Robson A, Greene J, Ansari N, et al. Eccrine porocarcinoma (malignant eccrine poroma): A clinicopathologic study of 69 cases. Am J Surg Pathol 2001;25:710-20.

7. Matloub HS, Cunningham MW, Yousif NJ, Sanger JR, Romano JA, Choi HY. Eccrine porocarcinoma. Ann Plast Surg 1988;20:351-5.

8. Montagna W, Parakkal P. The Structure and Function of the Skin (3rd edn). New York: Academic Press, 1974.

9. Grishkumar H, Kamineni S, Hwang RR, Levy J, Sadler R. Eccrine porocarinoma. Dermatol Surg 1997;23:583-4.

10. Puttick L, Ince P, Comaish JS. Three cases of eccrine porocarcinoma. Br J Dermatol 1986;115:111-6.

11. Mishima Y, Morioka S. Oncogenic differentiation of the intraepidermal eccrine sweat duct: Eccrine poroma, poroepithelioma and porocarcinoma. Dermatologica 1969;138:238-50.

12. Mehregan AH, Hasimoto K, Rahbari H. Eccrine adenocarcinoma. Arch Dermatol 1983;119:104-14.

13. Nakanishi Y, Matsuno Y, Shimoda T, et al. Eccrine porocarcinoma with melanocyte colonization. Br J Dermatol 1998;138:519-21.
14. Wittenberg GP, Robertson DB, Solomon AR, Washingon CV. Eccreineporocarcinoma treated with Mohs micrographic surgery. Dermatol Surg 1999;25:911-3.

15. Biondi E, Ranieri G, Nicolo A, Gasparini G. A unique case of eccrine porocarcinoma with pulmonary lymphangitis and pericardial involvement: Biological characterization and clinical aggressiveness. Oncology 2000;59:190-5.

16. Akiyoshi E, Nogita T, Yamaguchi R, Toyoda H, Kawahima M, Hidano A. Eccrine porocarcinoma. Dermatologica 1991;182:239-42.

17. Ritter AM, Graham RS, Amaker B, Broaddus WC, Young HF. Intracranial extension of an eccrine porocarcinoma. J Neurosurg 1999;90:138-40.

18. Roaf V, Chin N, Lynfield Y. Pigmented sweat gland tumour mimicking melanoma. Cutis 1997;59:43-6.

19. Hamanaka S, Otsuka F. Multiple malignant eccrine poroma and linear epidermal nevus. J Dermatol 1996;23:469-71.

20. Huet P, Dandurand M, Pignodel C, Guillot B. Metastasizing eccrine porocarcinoma: Report of a case and review of the literature. J Am Acad Dermatol 1996;35:860-4.

21. Katsanis WA, Doering DL, Bosscher JR. Vulvar eccrine porocarinoma. Gynaecol Oncol 1996;62:396-9.

22. Rook A, Wilkinson DS, Ebling FSG. Naevi and development of defects. In: Textbook of Dermatology, (editors?)Vol 15 th edn. Oxford: Blackwell Scientific Publications, 1992:445-526.

23. Gschnait F, Horn F, Lindlbauer R, Sponer D. Eccrine porocarcinoma. J Cutan Path 1980;7:349-53.

24. Abenzo P, Ackerman BA. Neoplasms With Eccrine Differentiation: Ackerman's Histologic Diagnosis of Neoplastic Skin Diseases: A Method by Pattern Analysis. Philadelphia: Lea \& Febiger, 1990:415-31.

25. Hara K, Kamiya S. Pigmented eccrine porocarcinoma: A mimic of malignant melanoma. Histopathology 1995:27:86-8.

26. Shaw M, McKee PH, Lowe D, Black MM. Malignant eccrine poroma: A study of twenty-seven cases. Br J Dermatol 1982;107:675-80.

27. Goedde TA, Bumpers H, Fiscella J, Rao U, Karakousis CP. Eccrine porocarcinoma. J Surg Oncol 1994;55:261-4.

28. Spiro RH, Huvos AG, Berk R, Strong EW. Mucoepidermoid carcinoma of salivary gland origin. A clinicopathologic study of 367 cases. Am J Surg 1978;136:461-8.

29. Barzi AS, Ruggeri S, Recchia F, Bertoldi I. Malignant metastatic eccrine poroma. Proposal for new therapeutic protocol. Dermatol Surg 1997;23:267-72.

30. El-domeiri AA, Brasfield RD, Huvos AG, Strong EW. Sweat gland carcinoma: A clinico-pathological study of 83 patients. Ann Surg 1971;173:270-4.

31. Hirsh LF, Enterline HT, Rosato EF. Sweat gland carcinoma. Ann Surg 1967;174:283-6.

32. Miller WL. Sweat gland carcinoma: A clinicopatholoical problem. Am J Clin Pathol 1967; 47:767-80.

33. Wertkin MG, Bauer JJ. Sweat gland carcinoma: Current concepts and surgical management. Arch Surg 1976;111:884-5. 